\title{
RESEÑA DE LIBROS.
}

\begin{abstract}
A neotropical companion: an introduction to the animals. Plants and ecosystems of the New World tropics. By John C. Kricher. Princeton University Press, Princeton, New Jersey. xxii + 436p. 1989.
\end{abstract}

\section{Un acompañante para incursionar en los neotrópicos}

Sin duda, mucho de lo poco que sabemos sobre la biología del ecosistema tropical se debe a la información derivada a partir de estudios en los neotrópicos. Nuestra visión actual de las constelaciones de organismos inmersos en el espectacular medio físico que constituyen los trópicos del nuevo mundo es aún fragmentaria y preliminar. Pero es ésta, sin duda, una visión fascinante: diversidades biológicas que en unas cuantas hectáreas sobrepasan las de países extratropicales completos, peces que dispersan semillas de árboles tropicales en el Amazonas, aves que forrajean en el dosel tropical, equipadas con modificaciones en el tracto digestivo que les permiten operar como si fueran verdaderos rumiantes voladores, etc. Mucha de esta fascinante información se encuentra dispersa en la literatura científica que, si de por sí es difícil de conseguir, mucho más lo es de analizar y presentar en forma amena y accesible. Un encomiable intento por salvar esta dificultad, se debe al "acompañante neotropical" de John C. Kricher. Es este un libro compacto, que ofrece una visión sintética general sobre estos espectaculares sistemas naturales, y que es de acceso a un público muy amplio. El no experto encontrar una útil introducción a las plantas y animales de los neotrópicos, y a la forma en que interactúan entre sí y con su ambiente físico. El experto encontrar además, una referencia útil a la información relevante sobre la identidad, ecología y evolución de los organismos neotropicales. Sin duda, a mi modo de ver, el volumen ser de particular utilidad para el botánico, zoólogo o ecólogo involucrado en la enseñanza sobre biología tropical.

El libro está organizado en diez capítulos. El primero ofrece un marco de referencia general sobre lo que es el ecosistema tropical; se describe aquí el escenario físico y (brevemente) las principales variantes de estos sistemas (selvas, savanas, páramos, manglares). El segundo capítulo describe los atributos "hacia el interior del sistema" (estructura, diversidad, estratificación, etc.), utilizando como modelo la selva húmeda. El tercero sigue esta secuencia enfatizando los aspectos funcionales de la misma (productividad, ciclaje de nutrimentos, sucesión). Un aspecto relacionado, de gran utilidad, que se anexa en este capítulo es el referente al uso del ecosistema tropical por culturas prehispánicas y contemporáneas. Estos tres capítulos descriptivos son útiles en que aclaran una serie de conceptos y atributos distintivos del ecosistema neotropical y dan pie a los dos siguientes que enfatizan los aspectos más evolutivos de las plantas y animales neotropicales. El capítulo 4 ofrece una visión estimulante de la ecología evolutiva relevante a los neotrópicos, incluyendo discusiones de adaptación, presiones de selección por fuentes bióticas y abióticas, gradientes de diversidad y las diferentes hipótesis a las que se ha recurrido para explicar la diversıdad tropical, patrones de 
radiación adaptativa (ejemplificada con murciélagos y mosqueros tirnidos) y especiación, sin faltar una discusión sobre la controversia actual de si el bosque tropical es o no una comunidad en equilibrio. El capítulo concluye con una visión un tanto acrítica, a mi modo de ver, sobre coevolución. Como muchos autores han discutido (p. ej. Janzen 1980) en muy pocos casos tenemos evidencias convincentes de que interacciones planta-polinizador, planta-herbívoro, dispersor-planta, y otras, sean el resultado de la coevolución. Por ejemplo, la abeja africanizada opera como un polinizador excelente de algunas plantas neotropicales aun cuando esta interacción, tan acoplada, no es coevolutiva: los interactuantes han estado en contacto trófico hace apenas unos años! La lección que se deriva de este y otros ejemplos similares no se discute (como tampoco, inesperadamente, se menciona a la abeja africanizada!).

Una derivación lógica de la discusión de la interfase planta-herbívoro, la evolución (que no necesariamente por coevolución) de defensas químicas por parte de la planta, es tratada en el siguiente capítulo sobre "La farmacia neotropical: drogas vegetales y sus consecuencias". Esta es una descripción interesante y atractiva que se extiende a aspectos etnobiológicos tales como "El hombre y las drogas". Mi mayor queja en este capítulo es que, tal vez por su derivación antropocéntrica, la terminología eco-evolutiva es en puntos inapropiada y aun engañosa ("...claramente las plantas tienen a los animales bajo su control" (p. 180). Habrá que ser cuidadoso con la teleología del libro.

Los dos capítulos siguientes (Aves Neotropicales y Un Bestiario de la Selva) me parecieron extremadamente útiles y amenos. Sin duda el estudiante y el ecólogo no especializados en los grupos zoológicos más evidentes del bosque neotropical, lograrn una apreciación mejor de estos componentes del sistema, no tan solo en términos de sus características distintivas, sino en algunos detalles importantes de su historia natural.

Sigue a ésto descripciones, un tanto superficiales, de dos grupos especiales de sistemas naturales neotropicales: sabanas y ecosistemas costeros incluyendo, estos últimos, manglares, comunidades de pastos marinos y arrecifes coralinos.

El epílogo al volumen lo constituye un capítulo sobre la problemática de la destrucción del bosque neotropical. Se incluye aquí una descripción del tristemente célebre proyecto de colonización y comunicación terrestre a través de parte de Amazonia, algunas reflexiones sobre usos alternativos de las selvas, una discusión sobre los posibles efectos de la deforestación tropical, y una anotación breve sobre algunas iniciativas internacionales para afrontar el problema. En este capítulo hay. sin duda, algunos puntos útiles pero en varias partes, claramente, se queda corto

El libro tiene un excelente material de apoyo que incluye: una guía de campo de aves neotropicales, una lista de libros importantes de consulta y otra de nombres científicos mencionados en el texto, un buen índice general, y la lista de referencias citadas. Es encomiable el esfuerzo del autor por incluir la literatura más relevante pero, indudablemente, mucha información de primera línea se dejó de lado. Notorio en ésto es la ausencia del excelente libro de Aves de Costa Rica (de F. Gary Stiles), y algunas contribuciones mexicanas de gran valía (particularmente en los campos de demografía 
vegetal tropical y ecofisiología vegetal). No obstante, es satisfactorio ver que el autor reconoce (en varios puntos) y termina el volumen con una alusión al iluminado mensaje, aún vigente, de Gómez-Pompa et al. (1972) de tratar a la selva como un recurso natural no renovable.

Fuera de los pocos "puntos negros" que he comentado, este es un libro extraordinariamente útil, ameno y altamente recomendable a la comunidad boténica mexicana y latinoamericana.

\section{LITERATURA CITADA}

JANZEN, D. H. 1980. When is it coevolution? Evolution 34:611-612.

GÓMEZ-POMPA, A., C. Vázquez-Yanes, y S. Guevara, 1972. The tropical rain forest: a nonrenewable resource. Science 177:762-765.

RODOLFO DIRZO. Centro de Ecología, Universidad Nacional Autónoma de México. Esta revisión se llevó a cabo mientras el autor se encontraba asociado al Missouri Botanical Garden (St. Louis, MO. EE. UU.), y con apoyo de una beca otorgada por la Fundación Jessie Smith Noyes. 